Preprint version of:

"Determination of the Blowing Agent Distribution in Rigid Polyurethane Foam”, M Svanström, O Ramnäs, J Cellular Plastics, 32:159-171, 1996.

DOI: $10.1177 / 0021955 X 9603200204$ 


\title{
Determination of the Blowing Agent Distribution in Rigid Polyurethane Foam
}

\author{
MAGDALENA SVANSTRÖM AND OLLE RAMNÄS* \\ Department of Chemical Environmental Science \\ Chalmers University of Technology \\ S-412 96 Göteborg \\ Sweden
}

\begin{abstract}
The amount and distribution of blowing agent in rigid polyurethane foam were determined by several methods, which are described and compared. A method for solvent extraction with subsequent gas chromatographic analysis was developed and found to be advantageous for CFC-blown foam along with a combustion method (the Schöniger method), where the chloride ions formed were determined by titration. The solvent extraction method was successfully applied to blowing agents in CFC-free foams as well. Three methods involving heating and weight-loss determination were evaluated. They are easy to use, but corrections for thermal decomposition of the polymer are needed. About half of the total amount of CFC-11 in the investigated polyurethane foams from district heating pipes was found to be dissolved in the polymer matrix.
\end{abstract}

\section{INTRODUCTION}

In a previous study [1], a method for the determination of cell gases in polyurethane foam was reported.

Typically, as much as half of the insulating capacity of a foam depends on the thermal conductivity of the cell gas $[2,3]$. If the partial pressure of a gas is lower outside the foam than in the foam, gas molecules will diffuse out of the foam, normally increasing its thermal conductivity. Concurrent diffusion of nitrogen and oxygen into the foam also contributes to the increase in thermal conductivity. However, most of the common insulating gases in rigid foam are also dissolved in the polymer matrix. This will affect the long-term thermal performance of the foam. Blowing agent diffusing out of the foam is partially replaced by a release from the polymer, tending to restore an equilibrium concentration [3]. Hence, the long-term thermal performance of an insulating foam can be predicted only if both the amount of blowing agent in the foam and its distribution between cell gas and polymer 
matrix are known. If the total content of blowing agent in the foam is high, it may also be present in condensed form in the cells.

There is a large difference in solubility between common blowing agents, as well as a large variability in the solubility of a specific blowing agent in different polymer matrixes [3, 4, 5]. Reported proportions of between 37 and $99 \%$ of CFC-11 in the vapor phase $[4,5$, $6,7,8,9,10]$ indicate uncertain determinations and estimations. It is difficult, if not impossible, to make exact predictions of the gas-solid distribution, since non-equilibrium conditions exist in the foam [11]. Some authors argue that blowing agents slowly migrate into the polymer matrix after the manufacture of the foam. This would cause a decrease in the concentration of blowing agent in the gas phase, adding to that due to outward diffusion $[4,5,8]$. There may also be a redistribution of cell gas components due to initial inhomogeneities in the foam. Other authors report that large amounts of blowing agent may be trapped in the solid when the foam is produced. As a result, the equilibrium solubility of the blowing agent in the solid may be exceeded shortly after manufacturing [11]. It is concluded that the need for reliable experimental determinations is great $[4,5,11]$.

Foam aging depends on initial conditions as well as the rates of inward diffusion of air and outward diffusion of blowing agents. The diffusion rates are greatly influenced by foam properties, gas partial pressures, temperature and the presence of diffusion barriers [12]. The distribution of blowing agent should consequently be determined not only shortly after manufacture but also after a period of aging under known conditions, to enable adequate predictions of the long-term thermal performance.

In earlier studies on the amount of blowing agent in polymeric foam, the total amount or the amount in the gas phase has been determined [7, $13,14,15]$. Little effort has been put into studies on the amount dissolved in the polymer matrix and the actual gas-solid distribution of blowing agent in the foam $[9,10]$. The purpose of this study is to elaborate, apply and compare different methods for determining the amount and the distribution of blowing agents in cellular plastics. 


\section{EXPERIMENTAL}

\section{Samples}

Polyurethane foams from seven different district heating pipes were chosen for the comparing analyses. Five foams were blown with CFC-11 (samples A-D, all 10 years old, and sample E, 20 years old); one was blown with carbon dioxide (sample F, 5 years old) and one was blown with cyclopentane (sample $\mathrm{G}$, new). The foam blown with carbon dioxide was used as a blank sample. All the pipes, except the new one, had been used in district heating systems. When the pipes were taken out of use, $10-30 \mathrm{~cm}$ long sections were cut from each pipe. The foam ends were sealed with a mixture of paraffin and beeswax, and the pipe samples were stored for about a year before the analyses were made. Samples A-C and $F$ had the same dimensions $\left(d_{i}=100 \mathrm{~mm}, d_{o}=225 \mathrm{~mm}\right)$; sample D was larger $\left(d_{i}=280 \mathrm{~mm}, d_{o}=400 \mathrm{~mm}\right)$ and sample $G$ was smaller $\left(d_{i}=80 \mathrm{~mm}, d_{0}=130 \mathrm{~mm}\right)$. Sample $E$ was delivered in pieces, without the steel pipe, and had a very large outer diameter and a $42 \mathrm{~mm}$ thick foam layer. The outer casing was $4-5 \mathrm{~mm}$ thick for sample A-C and E-G and $9 \mathrm{~mm}$ thick for sample D. All pipes had a polyethylene casing except sample $\mathrm{E}$, which had a polyvinyl chloride casing.

\section{Thermal weight-loss methods}

Three different methods based on heating were elaborated for the determination of blowing agents in polymeric foam.

A straightforward, but time-consuming method, involved heating of the foam in an oven and determination of the weight reduction. Two cylindrical samples $(20 \times 60 \mathrm{~mm})$ were cut from each foam. One of the cylinders was ground in a special sampling device [1], and the powder was collected in a cup. The remaining cylinder and the powder were placed in the oven $\left(120^{\circ} \mathrm{C}\right.$, atmospheric pressure). After a few days, the weight of the powder was constant, indicating that all of the CFC-11 or cyclopentane in the powdered foam had disappeared. The reduction in weight was determined. After three weeks, the temperature was increased to $150^{\circ} \mathrm{C}$ and $20-30$ small holes were made in the cylinder with a needle. After two further weeks, the weight of the cylinder was constant, and the weight loss was determined. The weight reduction of the cylinder indicates the total amount of blowing agent in the foam. The weight reduction of the powder reflects the amount of blowing agent dissolved in the solid polymer. 
A rapid thermal method for powdered foam made use of a combined oven-balance (Sartorius Moisture Analyzer 30), intended for moisture content determination. Foam powder (at least $5 \mathrm{~g}$ ) was collected on aluminum plates, which were put into the oven-balance. The temperature was increased from ambient to $150-160^{\circ} \mathrm{C}$ in $1-2$ minutes, and the weight of the sample was monitored continuously. The temperature was kept at $150-160^{\circ} \mathrm{C}$ until the weight had been constant for thirty seconds, after which the procedure was stopped automatically. The complete weighing procedure normally required about five minutes. The weight reduction of the powder corresponds to the amount of blowing agent dissolved in the solid polymer. In this case, the weight reductions were too small to be determined accurately by the balance. The reproducibility of the results was high (the standard deviation was less than $1 \%$ of the mean value) and if a rough and quick determination is needed, the oven-balance method is excellent. The method is not suitable for cylindrical foam samples, because of the slow diffusion processes in samples with closed cells.

A third applied thermal method is rapid but demands access to expensive equipment. Approximately $5 \mathrm{mg}$ of powdered foam was kept in nitrogen atmosphere on the balance of a thermogravimetric analyzer (Perkin-Elmer TGA7 Thermogravimetric Analyzer). The temperature was increased from 50 to $300^{\circ} \mathrm{C}$ in 12.5 minutes $\left(20.0^{\circ} \mathrm{C} \mathrm{min}{ }^{-1}\right)$. A weight/temperature curve was plotted automatically, permitting the weight reduction corresponding to the amount of blowing agent dissolved in the solid polymer to be determined. Very small amounts are analysed and since most foams have inhomogeneities, it is important to make sure that a representative part of the foam is used.

\section{Schöniger method}

For foams with chlorine-containing blowing agents, Lohmeyer [13] and Wan et al. [14] used a method, referred to as the Schöniger method, to study the total amount of blowing agent. The foam must be free from other chlorine-containing compounds, e.g. flame retardants, which otherwise may interfere with the analysis.

In the version of the method applied here, a foam sample and a powder sample from each foam $(30 \mathrm{mg})$ were burnt in a platinum basket in an Erlenmayer flask ( 1 litre) filled with oxygen. The combustion products were absorbed in water with a few drops of hydrogen peroxide. The aqueous solution was then diluted with isopropanol and $\mathrm{pH}$ was adjusted to 3.6 with perchloric acid. Diphenylcarbazone was added as an indicator, and the solution was titrated with mercury(II)perchlorate. The titration determines the amount of chloride ions formed from the 
sample, permitting the total amount of a chlorine-containing blowing agent in the foam to be calculated. For the powders, the amount of blowing agent dissolved in the solid polymer was obtained.

\section{Solvent extraction method}

Solvent extraction of blowing agents in plastic foam has earlier been performed by Ascough [15], using a food blender. In this study, a special grinding device, illustrated in Figure 1, was built to allow a more efficient extraction. Cylindrical samples of foam $(20 \times 40-50 \mathrm{~mm}$, depending on foam density) were ground in a metal cylinder filled with isopropanol. When the cell gas is released from the closed cells, the blowing agent is dissolved in the solvent. Most of the blowing agent in the polymer matrix dissolves into the isopropanol during the first 24 hours, but small increases in the concentration were observed for as long as two weeks. After sufficient extraction, the solvent was analysed by gas chromatography (GC). A polar GC column (6m x 1/8", Supelco SP-1000 as stationary phase) was used, on which CFC-11 and cyclopentane are eluted before isopropanol. The total amount of blowing agent in the foam sample was calculated from the GC results. On grinding, minor losses of blowing agent from the cell gases may occur.

\section{RESULTS}

\section{Cell gases}

Initially, a quantitative cell gas analysis was performed for each foam. The method applied is thoroughly described elsewhere [1]. It involves grinding of the foam and a subsequent gas chromatographic analysis of the released gases. The results are reported in Table 1 .

The cell gas analysis showed that the blowing agent in the cells of the cyclopentane-blown foam (sample G) was partially condensed. The liquid cyclopentane evaporates into the large gaseous volume of the sampling device during grinding of the foam. If the first calculations give a partial pressure of cyclopentane exceeding its vapor pressure at the specific temperature, it is assumed that the blowing agent is partially condensed. The results are then recalculated to correspond to the saturation concentration of blowing agent in the cell gas. About $30 \%$ of the cyclopentane in the cells turned out to be in condensed form.

The sum of the cell gases in Table 1 is less than $100 \%$ for each sample, because the gas phase also contains moisture and trace amounts of other compounds. Carbon dioxide is always formed when manufacturing a 
foam and is therefore always present as a co-blowing agent. The diffusion coefficient for carbon dioxide is higher than for the other reported gases. Sample D is 10 years old, but still contains a large amount of carbon dioxide and only a small amount of air, probably due to a thicker outer casing and a higher density than the other 10-year-old foams (samples A-C). Diffusion barriers, as high density and thick outer casing, slow down diffusion processes, causing a low outward diffusion of carbon dioxide and a low inward diffusion of air [11]. Sample E is 20 years old and contains less CFC-11 than the younger foams. Almost no air has yet entered the new cyclopentane-blown foam, and the content of carbon dioxide is still high. The pressure in the foam blown with carbon dioxide is low. This is expected since no other blowing agent remains when carbon dioxide diffuses out of the foam.

\section{Blowing agent in the polymer}

After the cell gas determinations, each foam was analysed by the methods described in the experimental part. In Table 2, the determinations of the blowing agent dissolved in the polymer matrix of the foam are compared. The weight loss for the foam blown with carbon dioxide was subtracted from the observed weight reductions given in parentheses, to correct for thermal decomposition of the foam. For the thermogravimetric method, the small weight reduction due to moisture leaving the foam below $107^{\circ} \mathrm{C}$ was subtracted for each sample (Figure 2). The thermal decomposition loss, observed between 107 and $250^{\circ} \mathrm{C}$ for the carbon dioxide-blown foam, was also subtracted for all other samples.

For all the pipes, the thermal weight-loss methods yielded higher values than the Schöniger method, which may indicate that the carbon dioxide-blown foam was inappropriate to use as a reference sample for thermal decomposition. For the 20-year-old sample E, the thermal methods applied indicated inconsistently high weight losses. Possibly, this foam was formulated in another way than the younger ones or oxidation may have weakened the foam, resulting in severe thermal breakdown. For this reason, sample $\mathrm{E}$ was not analysed by thermogravimetry. The results for the cyclopentane-blown foam are uncertain, because the correction for thermal degradation is of the same order of magnitude as the whole content of blowing agent in the polymer.

The Schöniger method can be used for all CFC-blown foams. It is not applicable to cyclopentane-blown foam which does not contain any chlorine. 
It is concluded that the content of CFC-11 in the polymer matrix was approximately $4 \%(\mathrm{w} / \mathrm{w})$ for the CFC-blown foams. For the cyclopentane-blown foam, the content of blowing agent was lower.

\section{Blowing agent in the foam}

In Table 3, results from the determinations of the total amount of blowing agent in the foams are compared. For the cylinder samples analysed by the oven heating method, values from the cell gas analyses were used to calculate adjusted weight reductions. The change, during heating, from the initial cell gas composition to the composition of air was thereby taken into account. The weights of the different gases in the foam before and after thermal treatment were considered. Then the weight loss for the carbon dioxide-blown foam was subtracted from the adjusted weight reductions, to correct for thermal decomposition of the foam. Because of the low cell gas pressure of the carbon dioxide-blown foam, the corrections were actually larger than the original weight reduction of $1.6 \%$.

The results from the Schöniger method and the solvent extraction method agree well. These are also the most reliable methods, since the thermal weight-loss methods all involve difficulties associated with corrections for the thermal decomposition of the foam. For cyclopentane-blown foam, solvent extraction should be preferred compared with the less reliable thermal methods.

\section{Distribution of blowing agent}

In Table 4, the calculated contents of CFC-11 or cyclopentane in the gas phase, the polymer phase, and the foam as a whole are given as weight percentages of the foam sample. Unfortunately, the results for the total content are higher than the sum of the results for gas and polymer phase. For the cyclopentane-blown foam (sample G), about $0.6 \%$ of the total weight of the foam was cyclopentane in condensed form. Efforts were made to calculate the distribution of the blowing agent between the gas phase and the polymer phase. Depending on how the results in Table 4 were combined, varying distribution values were obtained. However, the calculations indicate that about half of the total content of CFC-11 or cyclopentane in the foam is dissolved in the polymer. 


\section{DISCUSSION}

If the distribution of blowing agent in the foam is to be determined, no single method can be used alone. Methods are described for the determination of the total amount of blowing agent, the amount in the cell gas and the amount dissolved in the polymer. Two of these three parameters are required to determine the distribution of blowing agent between the gas and the polymer phase. A quantitative cell gas analysis also has to be made, if the gas-solid distribution of the blowing agent in the foam is to be determined accurately.

For CFC-blown foam, all the methods described in this paper can be used. All methods give reproducible values. The standard deviation is less than $1 \%$ for all methods except for the Schöniger method, for which the standard deviation is less than $3 \%$ of the mean value. A drawback of the Schöniger method is that a large and varying percentage of broken cells are obtained when preparing the small foam samples required. However, the Schöniger method must still be considered as reliable, mainly because no corrections for thermal decomposition (necessary in all thermal methods) are needed. For studies on the distribution of blowing agent in CFC-blown foam, the Schöniger method or the solvent extraction method should be used, preferably combined with a cell gas analysis.

Surprisingly, the total content of CFC-11 was almost the same in all 10 -year-old foams (samples A-D), regardless of the dimensions and densities. The results may indicate that the loss of CFC-11 still is too small to give significant differences. The results can also be explained by initial differences in the CFC-11-content.

The distribution of blowing agent is not expected to be exactly the same in foams with different formulations. However, the results indicate that about half of the total amount of CFC-11 was dissolved in the polymer matrix. Consequently, it is never enough to study only the cell gas composition if the long-term qualities of a foam are to be predicted. The cell gas composition can only give the current thermal conductivity of the foam. The results also implicate that a considerable amount of CFC-11 may be left in polyurethane foam waste. This strengthens the environmental incentives for recovery of polyurethane foam in refrigerators, insulation panels and district heating pipes. In Sweden, CFC-11 and other components, are already being recovered from most refrigerators.

As the use of stable chlorine-containing compounds is prohibited for environmental reasons, insulating foam will be made with chlorine-free 
blowing agents. Insulating gases for the future are likely to be carbon dioxide and different suitable hydrocarbons, e.g. cyclopentane. The solvent extraction method is probably the most reliable for chlorine-free foam. When equipment for gas chromatography is not available, a thermal method can be used. However, these methods involve difficulties concerning correction for thermal degradation of the foam.

To minimize the thermal decomposition, the foam should not be exposed to higher temperatures than necessary and should be heated for as short a time as possible. The results indicate high thermal degradation for aged samples. It is possible that structural changes, promoting thermal decomposition, have occured during aging. The thermal decomposition may be lower for the new cyclopentane-y blown $\leftarrow$ foam studied than for older foams. This is indicated (Table 3) by the higher value obtained from solvent extraction than from thermal methods for the cyclopentane-blown foam only. It is also likely that the thermal decomposition of carbon dioxide-blown foam differs from that of other foam samples, making it unsatisfactory as a blank sample.

\section{ACKNOWLEDGEMENT}

The financial support from NUTEK (The Swedish National Board for Industrial and Technical Development) and The Swedish District Heating Association is greatly appreciated.

\section{REFERENCES}

1. Svanström, M and O. Ramnäs. 1995. J. Cellular Plastics, 31:375-388.

2. Booth, R. J. and M. P. Drouin. 1989. J. Thermal Insulation, 13:97-104.

3. Andersson, S., O. Ramnäs and T. Rydberg. 1992. Swedish Environmental Protection Agency, Report 4032, Feb 1992.

4. Bomberg, M. and D. A. Brandreth. 1990. Insulation Materials, Testing and Applications, ASTM STP 1030, D. L. McElroy and J. F. Kimpflen, Eds., American Society for Testing and Materials, Philadelphia, 1990, pp 156-173. 
5. Bomberg, M. and C. Gilbo. 1989. J. Thermal Insulation, 13:74-83.

6. Brandreth, D. A. 1989. International Workshop on Long-Term Thermal Performance of Cellular Plastics. Sept 28-29, 1989, Huntsville, Ontario, Canada.

7. Norton, F. J. 1967. J. Cellular Plastics, Jan. 1967, pp 23-37. Also in Advances in Foam Aging, D. A. Brandreth, Ed., Caissa Editions, Yorklyn, Del., 1986.

8. Kumaran, M. K., M. T. Bomberg, R. G. Marchand, M. R. Ascough and J. A. Creazzo. 1989. J. Thermal Insulation, 13:123-137.

9. Gaarenstroom, P. D., J. B. Letts and A. M. Harrison. 1989. 32nd Annual Polyurethane Technical/Marketing Conference. Oct 1-4, 1989, San Francisco, California, USA, pp 163-168.

10. Steinle, H. 1971. Prog. Refrig. Sci. Technol., Proc. 13th Int. Congr. Refrig., pp 47-52.

11. Norton, F. J. 1982. J. Cellular Plastics, Sept/Oct, 1982, pp 300-318.

12. Kabayama, M. B. 1987. J. Thermal Insulation, 10:286-300.

13. Lohmeyer, S. 1982. Gummi Asbest Kunststoffe, 2, 35:66-70.

14. Wan, C., F. Tyler, N. Nienhuis and R. Bell. 1991. J. Cellular Plastics, 27:163-175.

15. Ascough, M. R. 1989. Int. Workshop on Long Term Thermal Performance of Cellular Plastics. Huntsville, Ontario, Canada, Sept. 28-29, 1989.

\section{BIOGRAPHIES}

\section{Svanström}

Magdalena Svanström, licentiate of engineering (Chemical Environmental Science, 1993), is a Ph. D. student at the Department of Chemical Environmental Science, Chalmers University of Technology. She is a member of an interdisciplinary research group at Chalmers, working in the field of CFC-free polyurethane foam. 


\section{O. Ramnäs}

Olle Ramnäs, Ph.D., is an University Lecturer at the Department of Chemical Environmental Science, Chalmers University of Technology. During the last decade, his main research area has been the analysis of organic air pollutants. He is a member of an interdisciplinary research group at Chalmers, working in the field of CFC-free polyurethane foam.

\section{KEYWORDS}

Polyurethane foam, Blowing agents, CFC-11, Cyclopentane, Gas/polymer distribution, Thermal methods, Schöniger, Solvent extraction 
Table 1. Results from cell gas analyses of polyurethane foam in seven district heating pipes.

\begin{tabular}{|c|c|c|c|c|c|c|c|}
\hline \multirow{2}{*}{$\begin{array}{c}\text { Sample } \\
\text { [blowing } \\
\text { agent] }\end{array}$} & \multicolumn{5}{|c|}{ Concentrations in cell gas $(\%, v / v)^{a}$} & \multirow{2}{*}{$\begin{array}{c}\text { Foam } \\
\text { densitya } \\
\left(\mathrm{kg} \mathrm{m}^{-3}\right)\end{array}$} & \multirow{2}{*}{$\begin{array}{c}\text { Pressure } \\
\text { in foam }^{\mathrm{a}} \\
(\mathbf{k P a})\end{array}$} \\
\hline & $\mathbf{O}_{2}$ & $\mathbf{N}_{2}$ & $\mathrm{CO}_{2}$ & CFC-11 & c-pentane & & \\
\hline A [CFC-11] & 11 & 35 & 0.9 & 51 & 0 & 85 & 110 \\
\hline $\mathrm{B}$ [CFC-11] & 14 & 48 & 0.1 & 35 & 0 & 80 & 140 \\
\hline $\mathrm{C}[\mathrm{CFC}-11]$ & 9.8 & 52 & 0.9 & 36 & 0 & 91 & 140 \\
\hline D [CFC-11] & 2.5 & 5.6 & 51 & 40 & 0 & 108 & 150 \\
\hline $\mathrm{E}$ [CFC-11] & 17 & 61 & 0.1 & 21 & 0 & 46 & 100 \\
\hline $\mathrm{F}\left[\mathrm{CO}_{2}\right]$ & 22 & 21 & 55 & 0 & 0 & 78 & 50 \\
\hline $\mathrm{G}$ [c-pentane] & 0.8 & 2.5 & 59 & 0 & 34 & 68 & 110 \\
\hline
\end{tabular}

a The results are mean values of at least two determinations for each foam.

Table 2. Concentration of CFC-11 or cyclopentane in the polymer matrix of polyurethane foams from district heating pipes, as determined for powdered foams by four different methods.

\begin{tabular}{|c|c|c|c|c|}
\hline \multirow{2}{*}{$\begin{array}{l}\text { Sample } \\
\text { [blowing } \\
\text { agent] }\end{array}$} & \multicolumn{4}{|c|}{ Concentration of CFC-11 or cyclopentane $(\%, w / w)^{a}$} \\
\hline & $\begin{array}{l}\text { Oven } \\
\text { heatingb }\end{array}$ & $\begin{array}{c}\text { Oven- } \\
\text { Balancec }\end{array}$ & $\begin{array}{l}\text { Thermo- } \\
\text { gravimetry }\end{array}$ & Schönigerc $^{c}$ \\
\hline A [CFC-11] & $6.0 \quad(7.6)$ & $5.3(6.8)$ & $5.6(7.3)$ & 4.2 \\
\hline $\mathrm{B}$ [CFC-11] & $5.8 \quad(7.4)$ & $5.1(6.6)$ & $6.4(7.8)$ & 3.8 \\
\hline $\mathrm{C}[\mathrm{CFC}-11]$ & $5.5 \quad(7.1)$ & $4.4(5.9)$ & $6.2(7.6)$ & 3.7 \\
\hline $\mathrm{D}$ [CFC-11] & $5.8 \quad(7.4)$ & $5.0(6.5)$ & $6.3(7.6)$ & 4.0 \\
\hline $\mathrm{E}[\mathrm{CFC}-11]$ & $10.1(11.7)$ & $7.1(8.6)$ & - & 2.8 \\
\hline $\mathrm{F}\left[\mathrm{CO}_{2}\right]$ & $0 \quad(1.6)$ & $0 \quad(1.5)$ & $0 \quad(1.3)$ & 0 \\
\hline $\mathrm{G}$ [c-pentane] & $0.9 \quad(2.5)$ & $1.1(2.6)$ & $1.8(3.3)$ & - \\
\hline
\end{tabular}


Table 3. Total content of CFC-11 or cyclopentane in polyurethane foams from seven district heating pipes, as determined by three different methods.

\begin{tabular}{|c|c|c|}
\hline Sampl & Concentration of CFC-11 or $\mathrm{c}$ & entane $(\%, w / w)$ \\
\hline agent & Oven heatinga,b & Solvent extractionc \\
\hline
\end{tabular}

$\begin{array}{lcccc}\text { A [CFC-11] } & 8.9(10.5) & 7.0 & 6.3 \\ \text { B [CFC-11] } & 9.6(11.5) & 7.9 & 7.9 \\ \text { C [CFC-11] } & 8.9(10.8) & 7.3 & 6.0 \\ \text { D [CFC-11] } & 8.8(11.0) & 7.2 & 5.9 \\ \text { E [CFC-11] } & 14.2(16.1) & 5.1 & - \\ \text { F [CO }] & 0 & (1.6) & - & 3.2 \\ \text { G [c-pentane] } & 2.8(4.9) & - & \end{array}$

aValues in parentheses are the original weight reductions of the foam cylinders, without correction for thermal decomposition and the change in the cell gas composition.

bMean values of three determinations.

cMean values of two determinations.

Table 4. Content and gas-polymer distribution of CFC-11 or cyclopentane in investigated polyurethane foams.

\begin{tabular}{llll}
\hline $\begin{array}{c}\text { Sample } \\
\text { [blowing } \\
\text { agent] }\end{array}$ & CFC-11 or cyclopentane & $(\%, w / w)$ \\
& Gas phase & Polymerb & Totalc \\
\hline & & & \\
A [CFC-11] & 2.8 & 4.1 & 6.6 \\
B [CFC-11] & 2.8 & 3.6 & 7.9 \\
C [CFC-11] & 2.5 & 3.6 & 7.2 \\
D [CFC-11] & 1.8 & 3.9 & 5.2 \\
E [CFC-11] & 1.4 & 2.7 & 3.2 \\
G [c-pentane] & 1.3 & 1.3 & \\
\hline
\end{tabular}

aCalculated from the cell gas analysis.

bCalculated from the powder Schöniger values. For the cyclopentane-blown foam (sample G), data were obtained from the thermal methods. Data from Table 2 recalculated to represent the percentage of the foam weight and not the polymer weight. If a cell gas analysis can not be made, about $4 \%$ of the sample weight should be assumed to be cell gases.

cMean of the Schöniger and the solvent extraction values in Table 3. 


\section{LEGENDS TO FIGURES}

Figure 1. Equipment used for solvent extraction of blowing agents. The foam sample is ground in the metal cylinder filled with the solvent.

Figure 2. Weight/temperature curve from analyses of one CFC-blown, one carbon dioxide-blown and one cyclopentane-blown polyurethane foam, on a thermogravimetric analyzer (Perkin-Elmer TGA7). 

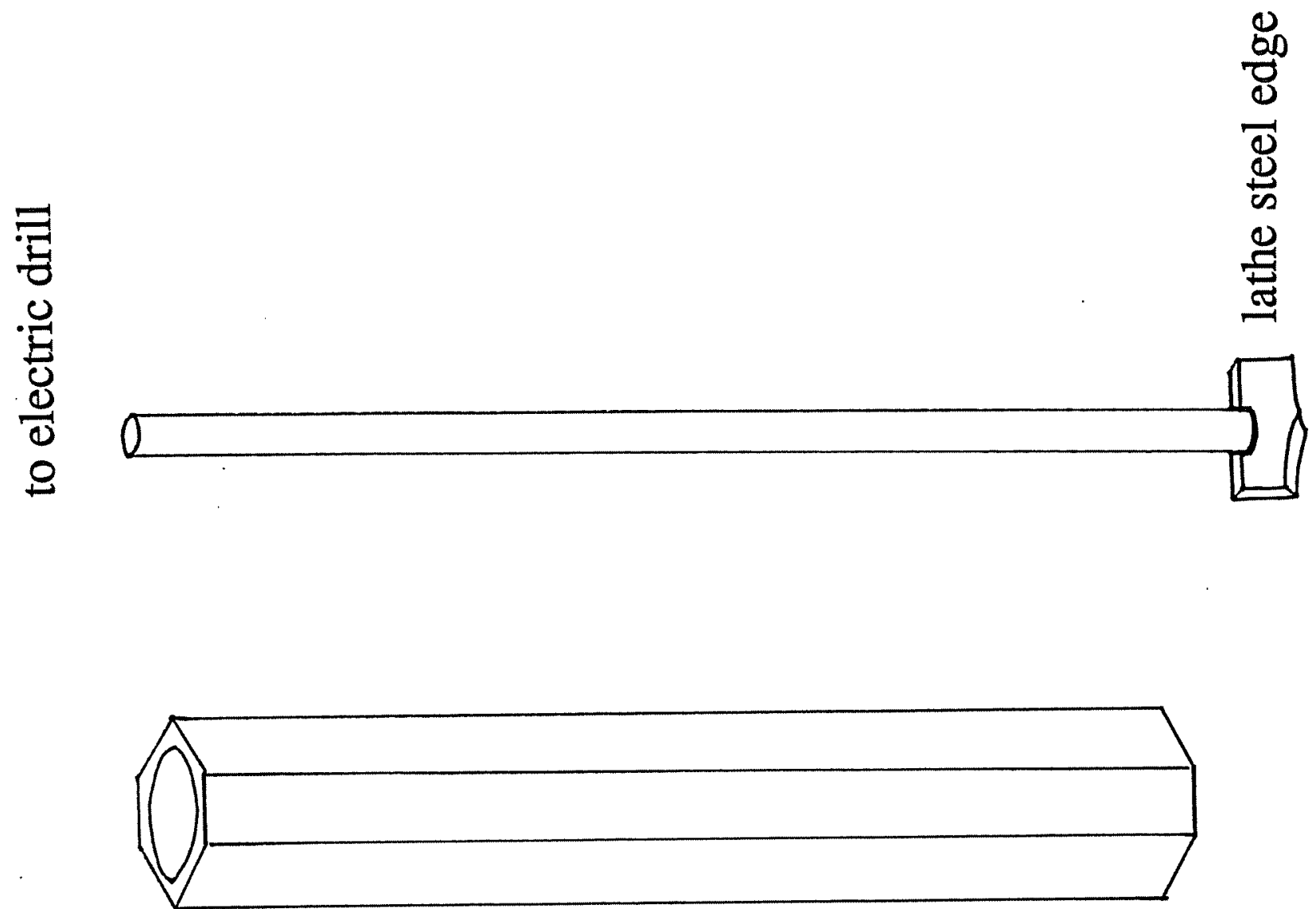

告

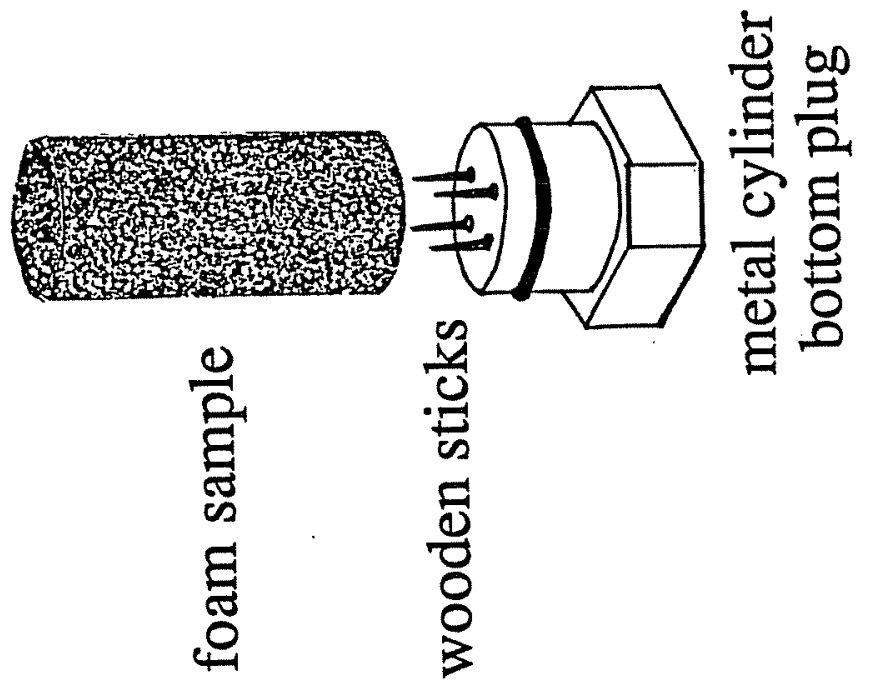




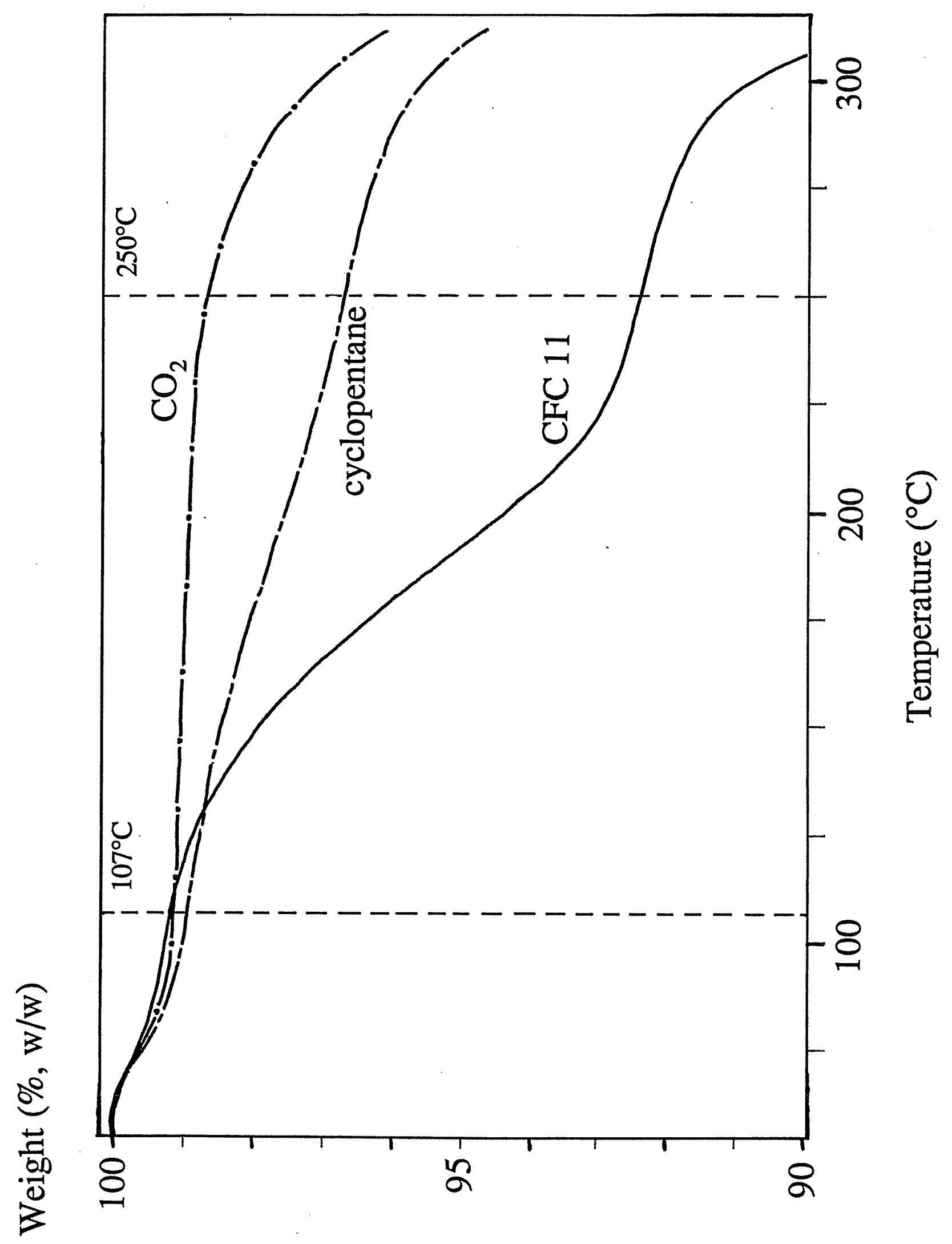

